\title{
What is critical?
}

\section{Bob Jessop and Ngai-Ling Sum}

This is pre-copy-edited version of a commentary piece published in 2016 in Critical Policy Studies, 10 (1), 105-109, http://dx.doi.org/10.1080/19460171.2015.1129352

\begin{abstract}
This article describes the meta-theoretical and theoretical foundations of one approach to critique that moves through up to eight analytically distinct steps. This critique begins with the identification of specific discourses and discursive practices and moves progressively towards a critique of ideology and domination and then to a critique of the factors and actors that, through diverse mechanisms of variation, selection, and retention, reproduce these ideological effects and patterns of domination as a basis for proposing and acting upon emancipatory projects that involve a variable mix of reform and revolution. An important part of these procedures is to deconstruct and demystify sedimented, naturalized discourses and social practices and to propose alternatives based on explicitly stated principles of justice and fairness.
\end{abstract}

\section{Introduction}

There are many modes of critique. Those most relevant to readers of this journal involve 'a critical attitude of mind' that goes beyond assessing the empirical validity of factual analysis or the technical-instrumental practicality of specific social arrangements. The approach to critique developed in our individual and joint work unfolds in a series of steps that lead to critiques of ideology and domination and culminate in proposals for sub- or counter-hegemonic alternatives and corresponding actions. Our suggestions do not derive from some continuing commitment to an as yet unrealized Enlightenment project or from other external, transcendental criteria. Instead they are grounded in specific, conjunctural analyses that rest on explicit and contestable entry-points and standpoints (Sum and Jessop 2013; Jessop 2015; on modes of critique, see also Demirović 2008; Rehman 2013; and Sayer 2009). 
Our approach draws on six meta-theoretical and theoretical approaches: complexity theory, critical realism, the strategic-relational approach, the Marxist critique of political economy and analogous emancipatory critiques of exploitation and/or domination, Foucauldian work on truth regimes, and cultural political economy. Some of these sources suggest limits to critique, others elaborate possible entrypoints and standpoints, and, taken together, they indicate the preconditions for critique and the possibility of a critique of critiques.

1. Complexity theory posits that, as the world can never be grasped in all its complexity, actors must reduce it cognitively and practically as a condition of 'going on'. The resulting imaginaries are always partial, provisional, contextually situated, and historically conditioned. This disqualifies any critique that a discourse 'misrepresents' a complex reality about which, thanks to direct and complete access thereto, the critic has full and accurate knowledge. But it does not exclude other kinds of critique based on secondorder observation of specific forms of misrecognition that reveal the blindspots of given imaginaries that 'cannot see what they cannot see' (Luhmann 1990, 85).

2. Critical realism distinguishes the intransitive from transitive moments of scientific investigation. The intransitive moment comprises the external world taken as an object of inquiry and could include its social (meaningful) aspects as seen by a disinterested observer; the transitive moment denotes the scientific practices and communities that investigate the external world. As an 'underlabouring' approach, critical realism examines, critiques, refines, and reflects on the ontological, epistemological, methodological, and substantive presuppositions of different philosophical and scientific schools and paradigms. It also emphasizes the scope for disjunctions between empirical evidence, actual events and processes, and their underlying causes in real mechanisms, tendencies, counter-tendencies, affordances, and liabilities (Sayer 2000).

3. The strategic-relational approach explores the biases inscribed in specific structures, their differential constraints and opportunities for specific actors operating with specific spatio-temporal horizons of action; it also explores actors' capacities to reflect on strategic contexts and conjunctures and modify 
these biases (Jessop 2007).

4. The Marxist critique of political economy is a paradigmatic example of critique in three respects. It offers an epistemological critique of the basic categories of classical and vulgar political economy and interprets them as expressions of capitalist social relations; it notes the disjunction between these categories and fundamental features of these relations that these categories ignore, deny, invert, or otherwise distort; and it elaborates an alternative account based on the contradictions, real tendencies and counter-tendencies, and contingent laws of motion of the capitalist mode of production and shows how these are connected with, and in part constituted by, the mystifying categories of bourgeois political economy (for example, Marx 1967, 1972).

5. There are more modes of knowledge production than scientific practice, of course, and Foucault's concept of 'truth regimes' provides a powerful entrypoint for describing and explaining knowledge claims and their effects on social practices (Foucault 1980). Gramsci's critical notes on intellectuals, hegemony, and common sense is also relevant here (Gramsci 1975; for a comparison of Foucault and Gramsci, see Sum 2015).

6. Cultural political economy draws on these and other approaches to inform a critique of semiosis (sense- and meaning-making) and the effects of structuration - hence for developing the critique of ideology and a critique of domination (Sum and Jessop 2013).

We combine these sources to indicate eight steps in developing a critique. These are presented in a logical sequence that does not match the order in which our theoretical sources were listed. Furthermore, actual critical practice will tend to move backwards and forwards among them. Critique can start with semiosis and its articulation into specific imaginaries, discourses, and discursive practices or with structuration in the form of specific sets of social relations, institutional orders, or broader social arrangements. Here we begin with semiosis.

1. Recognize the role of semiosis as a heterogeneous pool of intersubjective meanings that provide the 'raw materials' of complexity reduction through sense- and meaning-making (as opposed to through structuration) (Sum and Jessop 2013). This pool does not predetermine specific propositions, 
statements, arguments, frames, or imaginaries and, because sense- and meaning-making are ontological necessities of social existence, to describe this pool as ideological in itself would involve a self-defeating 'pan-ideologism' in which all discourses are ideological. An effective Ideologiekritik must always be directed against specific articulations of these materials.

2. Identify social imaginaries, i.e., specific clusters of meaning (or semiotic systems), describe their form and content; and, within these imaginaries, focus on specific arguments, discourses, social practices, and so on.

3. Develop an immanent, reasoned critique of the selected objects based on deficiencies in their internal assumptions, categories, problematization, and argumentation, with a view to disclosing empirical inadequacies, theoretical inconsistencies and anomalies, silences, exclusions, contradictions, or other defects. This kind of critique differs from mere criticism because the grounds of problems are also identified and explained (Rehman 2013: 5-8; Sayer 2009). This step can extend to a moral critique that reveals and evaluates the often implicit ethical and moral values, sentiments, commitments, feelings, spatio-temporal horizons of action, attitudes to the environment, and so on, that inform the critiqued object(s). This step does not yet amount to an Ideologiekritik because, 'whereas all ideology is made of ideas, not all ideas are ideological' (Larrain 1983: 21). Nonetheless an immanent critique may be extended to the practical consequences of incoherence or incompleteness in the imaginaries, arguments, etc., that are at stake.

4. Identify the interests that are privileged or favored by the critiqued object in specific periods or conjunctures, whether this is due to bad faith or results from ideological assumptions inscribed in language and other forms of signification thanks to the naturalization, reification, or uncritical fetishization of specific discourses and social facts. This is where Ideologiekritik begins.

5. Describe the role, if any, of the critiqued object in reproducing one or more durable, structured forms of social domination that serve particular interests. This is the stage of a Herrschaftskritik, i.e., the critique of the various forms and intersections of patterns of social domination and, where relevant, domination over nature and the role of the critiqued object in creating, selecting, institutionalizing, and sedimenting domination. 
6. Explore in turn the social and material bases that sustain the critiqued object, how it has been consolidated, and the discursive, structural, technological, and agential selectivities involved therein. This is the stage of sociological critique, broadly defined.

7. Propose alternative interpretations and strategies, based on normative commitments that differ from those articulated, or discoverable, in discourses or social arrangements in question, to facilitate the emancipation of subaltern social forces (and, perhaps, dominant ones too) from the harmful effects of the pattern of domination (discrimination, exclusion, exploitation, oppression) that is legitimated, naturalized or reproduced through the critiqued object. This involves cognitive, practical, and normative concerns with the identities, subjectivities, and interests of the forces engaged, or to be mobilized, in relevant struggles for emancipation.

8. Recognize that an effective critique must go beyond ideology and domination and acquire (counter-)hegemonic force, a material base in social development, and support from social forces that can implement the new strategies. This is likely to require a range of struggles oriented to different spatio-temporal horizons of action and mobilizing different social forces in a variable mix of struggles oriented to a dialectic of reform and revolution in a process characterized by trial-and-error experimentation, strategic learning, and, eventually, fundamental changes in the structural bases of domination. There is no critique as powerful as one whose time has come.

This approach to critique can also be applied to itself, other accounts of critique, and specific cases. Relevant questions include: how do their ontological, epistemological, methodological, and ethical horizons compare with those of other approaches? How did they emerge, what are their conditions of possibility, what is distinctive about their practice of critique, what kind of knowledge claims do they produce, what are their normative commitments, and do they reproduce their own forms of ideology and domination?

Only when the analysis reaches steps four and five could one hope to show that specific sense- and meaning-making systems legitimize the orders of discourse, social forms, and social practices associated with particular hegemonic and/or 
dominant social arrangements. These systems are all the more powerful, the more they become part of common sense and get embedded in everyday social practices. One should not limit Ideologiekritik to the framing and content of beliefs - it also concerns their forms of 'inscription' (the field of sociologistics, 'mediology', and modes of communication - see, for example, Debray 2004) and the structurallyinscribed strategic selectivities that condition who gets the chance to 'speak'. Finally, whether a critiqued object (whether a social imaginary, discourse, text, social practice, social relation, institution, etc.) has 'ideological' effects depends on the form of hegemony or domination at stake: this could be capitalist, patriarchal, heteronormative, 'racial', national, regional, and so on. Thus it might have non-trivial ideological effects as regards, say, capitalism but not regarding patriarchy (or vice versa). In short, Ideologiekritik requires a clear entry-point and standpoint and conjunctural referent rather than being conducted as if ideological effects are alwaysalready present as immanent features of specific discourses and social practices.

At stake in the critique of domination are the effects of the structuration of social relations and how they operate in biased ways 'behind the backs' of the relevant agents. Of interest is how discursive, structural, technological, and agential selectivities are condensed to form specific dispositives that help to secure hegemonies and dominations. While discursive selectivities are more relevant to Ideologiekritik, Herrschaftskritik pays more attention to structural and technological selectivities. At special interest here is how these selectivities reproduce specific semiotic, social, institutional, and spatio-temporal fixes that support the reproduction of economic, political, and social domination (Sum and Jessop 2013).

All eight steps are needed to deliver a critique that not only has logical force, theoretical appeal and political resonance but also demonstrates its practical relevance in showing that 'another world is possible'. This does not commit the critic to (1) a utopian belief in a social world with no traces of ideology or domination or (2) a relativist position that all sets of social relations are equally bad, neutral, or good. Within these limits convictions are contestable and must be justified. Reforms must be judged not only in terms of how they improve the quality of life of subaltern groups but also in terms of how and how far they create conditions conducive over time to a break with existing relations of domination. Emancipation is never achieved once 
and for all. There will be no end to struggles to maintain the scope for democratically accountable challenges to new forms of domination and to address the ethicopolitical demands of having regard to the least advantaged in world society.

\section{Acknowledgements}

We are grateful to Frank Fischer for the opportunity to contribute to this forum and to Alex Demirović, Norman Fairclough, Andrew Sayer, and Ruth Wodak for discussions on the theme.

\section{References}

Debray, R. 2004. Transmitting Culture. New York: Columbia University Press.

Demirović, A. 2008. 'Leidenschaft und Wahrheit. Für einen neuen Modus der Kritik'.

In Kritik und Materialität, edited by A. Demirović, 9-40. Münster: Westfälisches Dampfboot.

Foucault, M. 1980. Power/Knowledge: Selected Writings and Other Interviews 19721977. Brighton, UK: Wheatsheaf.

Gramsci, N. 1975. Quaderni del Carcere, edizione critica dell'Istituto Gramsci, 4 volumes. Turin: Einaudi

Jessop, B. 2007. State Power: A Strategic-Relational Approach. Cambridge: Polity. Jessop, B. 2015. 'Kritik-Staat-Emanzipation'. In Perspektiven und Konstellationen kritischer Theorie, edited by D. Martin, S. Martin, and J. Wissel, 83-103. Münster: Westfälisches Dampfboot.

Larrain, J. 1983. Marxism and Ideology. Atlantic Highlands, NJ: Humanities Press. Luhmann, N. 1990. Essays in Self-Reference. New York: Columbia University Press. Marx, K. 1967. Theories of Surplus Value, 3 volumes. London: Lawrence \& Wishart. Marx, K. 1976. Capital, 3 volumes. London: Lawrence \& Wishart. Rehman, J. 2013. Theories of Ideology: The Powers of Alienation and Subjection. Leiden: Brill.

Sayer, A. 2000. Realism in the Social Sciences. London: SAGE.

Sayer, A. 2009. 'Who's afraid of critical social science?' Current Sociology 57, 76786. 
Sum, N.L. 2015. 'Cultural political economy of competitiveness, competition, and competition policy in Asia', Distinktion: Scandinavian Journal of Social Theory 16 (2), 211-28.

Sum, N.L. and B. Jessop 2013. Towards a Cultural Political Economy: Putting Culture in its Place in Political Economy. Cheltenham, UK: Edward Elgar. 